\title{
Análise do impacto de um minicurso de matemática básica para a graduação em engenharia
}

DOI: 10.37702/2175-957X.COBENGE.2021.3593

Ana Marta Souza - anamartaengenharia@gmail.com

Universidade Federal de Uberlândia

Rua Jangadeiros 201

38412-016 - Uberlândia - MG

Ana Teresa Taveira Bachur - tete.t.bachur@gmail.com

Universidade Federal de Uberlândia

Rua Santos Pereira 429

14401-130 - Franca - SP

Arthur Barbosa Gomes - arthur_bg@hotmail.com

Universidade Federal de Uberlândia

Rua Quartzo 130

35162-113 - Ipatinga - MG

Daniel Dias Barbosa - danieldias_barbosa@hotmail.com

Universidade Federal de Uberlândia

Rua do estudante 40

38413-171 - uberlandia - MG

Tássio de Farias Gomes - tassiofarias17@gmail.com

Universidade Federal de Uberlândia

Rua Santa Helena Qd. 44 Lt. 0100

74905-040 - Goiânia - GO

Resumo: $O$ presente artigo visa avaliar os impactos da aplicação de um curso de matemática básica no desempenho dos estudantes de disciplinas de ciências exatas, principalmente para os cursos de engenharia. Estudou-se características que seriam relevantes no desempenho dos alunos, como o tipo de formação básica, se houve apoio de cursos pré-vestibulares, o desempenho desses tanto no curso em si, quanto nas disciplinas às quais estão matriculados. Os dados apresentados foram dispostos de forma a identificar os principais empecilhos para um bom desenvolvimento em matérias associadas à matemática. Os resultados apontaram 
uma discrepância entre os alunos oriundos de escolas públicas e particulares. Mesmo assim, a maioria dos alunos relataram certa melhora com relação à matemática e à confiança em relação à disciplina.

Palavras-chave: Curso de matemática básica, Influência no aprendizado, Desempenho de alunos em ciências exatas. 


\section{Análise do impacto de um minicurso de matemática básica para a graduação em engenharia}

\section{INTRODUÇÃO}

O ensino de matemática é um problema no sistema educacional brasileiro, principalmente nas instituições de educação básica (educação infantil, ensino fundamental e ensino médio). A última edição do Programa Internacional de Avaliação de Estudantes (Pisa) aconteceu em 2018 e expôs que o Brasil é o pior país da América Latina em matemática. Os resultados da avaliação apontaram que $68,1 \%$ dos alunos não possuem nível básico de matemática.

A situação torna-se mais agravante quando se compara o rendimento das escolas particulares com as escolas públicas. A diferença entre as notas no Pisa pode chegar até 33,6 \% (Portal Mec, 2018). O Exame Nacional do Ensino Médio (Enem) também reflete o abismo entre o ensino privado e público. De acordo com dados do Enem 2017, a rede estadual apresenta desempenho inferior em todas as áreas da prova em relação às escolas privadas, sendo que em matemática essa distância pode chegar até 67 \% (Gamba et al, 2018).

O desafio para o ensino de matemática não é exclusivo da educação básica. As Instituições de Ensino Superior (IES) também enfrentam graves problemas de rendimento estudantil em algumas disciplinas nas ciências exatas. Especificamente nos cursos de engenharia, em que o ciclo básico dura em torno de 2 anos e apresenta disciplinas como Cálculo, Geometria Analítica e Álgebra Linear, as taxas de reprovação são regularmente altas. Um estudo na Universidade Federal Fluminense apontou que entre 1996 e 2000 a taxa de reprovação na instituição para disciplinas de Cálculo Diferencial e Integral variou entre $45 \%$ e $95 \%$ (Rezende, 2003).

Uma das justificativas mais comuns para o baixo desempenho reside na formação matemática precária no ensino básico, ou seja, dificuldade em assuntos que são prérequisitos para o meio universitário (Passo, 2007). Esse insucesso nas disciplinas da faculdade, por vezes, provoca abandono do curso ou até mesmo influência na decisão de não se matricular em um curso com essas disciplinas obrigatórias. O reflexo disso está nas elevadas taxas de desistência, como mostra o levantamento entre 2001 e 2011, no qual apenas $44 \%$ dos alunos de engenharia se graduaram (G1, 2013).

Diante dessa situação, o grupo de Programa de Educação Tutorial da Faculdade de Engenharia Mecânica (PETMEC) da Universidade Federal de Uberlândia (UFU) desenvolveu um curso de matemática básica para os ingressantes das graduações em ciências exatas, principalmente engenharias. O propósito do curso foi o nivelamento de conhecimento de matemática básica dos alunos para um melhor desempenho nas matérias de ciclo básico, buscando colaborar para a redução das evasões. Esse projeto está em alinhamento com as diretrizes dos grupos PET, em que se busca contribuir para a qualidade da formação dos alunos de graduação, de forma a diminuir a evasão e promover o sucesso acadêmico (Diário Oficial da União, 2013).

O principal objetivo deste trabalho é analisar a influência que o curso de matemática básica obteve sob os alunos nas disciplinas atuais prestadas, na sua confiança com relação à matemática e em seu crescimento acadêmico e profissional. Ademais, visa definir o perfil dos participantes do curso e como isso influencia em seu conhecimento prévio e resposta após a atividade. 


\section{METODOLOGIA}

O curso de matemática básica foi ministrado entre os dias 08/03/21 e 19/03/21 de forma totalmente remota e ao vivo através da plataforma Google Meets. Além disso, as aulas foram gravadas e disponibilizadas no Youtube apenas para os alunos participantes. Essas aulas começavam às $19 \mathrm{~h}$ e duravam em média 2 horas, nelas o ministrante apresentava o assunto programado para o dia com o auxílio de slides e um quadro branco. Após as aulas, os alunos eram apresentados a uma lista de exercícios referente ao conteúdo estudado e seu gabarito.

A bibliografia usada para estruturar o curso foi o livro do Manoel Paiva da editora Moderna (Paiva, 2010) e a ementa utilizada para o curso está representada pela Tabela 1. Como pode-se observar, foram realizados 9 dias de aula e o décimo foi destinado para que os alunos pudessem sanar suas dúvidas relacionadas ao conteúdo abordado. A escolha dos tópicos teve como fundamento abordar os conhecimentos prévios mais importantes para o bom desempenho nas disciplinas dos primeiros períodos letivos, como Cálculo Diferencial e Integral.

Tabela 1 - Ementa do Curso de Matemática Básica

\begin{tabular}{|c|c|}
\hline Dia de Aplicação & Ementa trabalhada \\
\hline $\begin{array}{l}08 / 03 / 2021 \\
\text { Segunda-Feira }\end{array}$ & $\begin{array}{l}\text { Operações básicas e fundamentos da } \\
\text { Matemática }\end{array}$ \\
\hline $\begin{array}{l}\text { 09/03/2021 } \\
\text { Terça-Feira }\end{array}$ & Polinômios \\
\hline $\begin{array}{l}\text { 10/03/2021 } \\
\text { Quarta-Feira }\end{array}$ & Conjuntos e conjuntos numéricos \\
\hline $\begin{array}{l}\text { 11/03/2021 } \\
\text { Quinta-Feira }\end{array}$ & $\begin{array}{c}\text { Funções I:Introdução, classificação e } \\
\text { inversibilidade) }\end{array}$ \\
\hline $\begin{array}{l}12 / 03 / 2021 \\
\text { Sexta-Feira }\end{array}$ & $\begin{array}{c}\text { Funções II: Funções polinomiais e funções } \\
\text { modulares }\end{array}$ \\
\hline $\begin{array}{c}15 / 03 / 2021 \\
\text { Segunda-Feira }\end{array}$ & $\begin{array}{l}\text { Funções III: Funções exponenciais e } \\
\text { logarítmicas }\end{array}$ \\
\hline $\begin{array}{l}\text { 16/03/2021 } \\
\text { Terça-Feira }\end{array}$ & $\begin{array}{c}\text { Trigonometria I: Arcos e trigonometria no } \\
\text { triângulo retângulo }\end{array}$ \\
\hline $\begin{array}{l}\text { 17/03/2021 } \\
\text { Quarta-Feira }\end{array}$ & $\begin{array}{c}\text { Trigonometria II: Trigonometria no círculo e } \\
\text { relações trigonométricas }\end{array}$ \\
\hline $\begin{array}{l}\text { 18/03/2021 } \\
\text { Quinta-Feira }\end{array}$ & $\begin{array}{l}\text { Trigonometria III: Equações, inequações e } \\
\text { funções trigonométricas }\end{array}$ \\
\hline $\begin{array}{l}\text { 18/03/2021 } \\
\text { Sexta-Feira }\end{array}$ & $\begin{array}{l}\text { Finalização e apoio a dúvidas } \\
\text { remanescentes }\end{array}$ \\
\hline
\end{tabular}

Fonte: Autoral

Após aproximadamente um mês do fim do curso, esses alunos foram submetidos a um formulário dedicado a avaliar os impactos e possíveis mudanças que o curso oferecido gerou neles. Esse prazo foi estipulado para que os participantes pudessem aplicar os conhecimentos adquiridos em atividades acadêmicas cotidianas, como avaliações das disciplinas às quais participavam. As perguntas do formulário tocavam aspectos como identificação do perfil do aluno, utilidade do material do curso, compreensão do conteúdo, mudança em sua confiança com relação à matemática, entre outros.

Para melhor representatividade dos resultados, o formulário foi disponibilizado apenas para os alunos com frequência igual ou superior a $80 \%$ nos 10 dias de atividades. 
Após a coleta desses dados, foi feita uma análise comparativa entre as informações adquiridas a fim de compreender melhor o público e possíveis melhorias que o curso trouxe. Também foi possível correlacionar as influências dessa atividade e conhecimentos anteriores à graduação em função do tipo de instituição que o aluno completou seu ensino médio.

\section{RESULTADOS}

Foi constatado que 60 alunos participaram em pelo menos um dia do curso e, desses, 29 estiveram presentes entre 6 e 10 dias. Como a atividade teve uma extensa duração, o número de participantes diários variou entre 22 e 42 estudantes. Quanto ao formulário de avaliação, 20 alunos que obtiveram pelo menos $60 \%$ de presença responderam ao formulário.

\subsection{Perfil dos participantes}

A primeira parte do formulário confeccionado para esse curso consistia em determinar qual o perfil de alunos que a atividade abrangeu. Dessa forma, foi apontado que a faixa etária estava entre 18 e 23 anos. Após isso, indagou-se qual curso superior o participante estava matriculado e, segundo a Figura 1, constatou-se que $60 \%$ do público consistia em alunos de engenharia mecânica, mecatrônica ou aeronáutica. Os 40 \% restantes se dividiam entre ciências contábeis, gestão da informação, ciências biológicas, química industrial e fisioterapia.

Outro parâmetro levantado foi se o aluno já havia cursado outra graduação superior e, em caso afirmativo, se já era portador de diploma. Obtivemos um resultado que $95 \%$ do público atingido consistia em ingressantes que nunca tiveram contato com o ensino superior. Destes, apenas um aluno já havia cursado outro curso superior, mas não havia se graduado. Essa relação está representada pela Figura 2.

Figura 1 - Gráfico ilustrando a relação entre alunos de engenharia e alunos de outras graduações presentes no curso.

Qual curso você está atualmente matriculado?

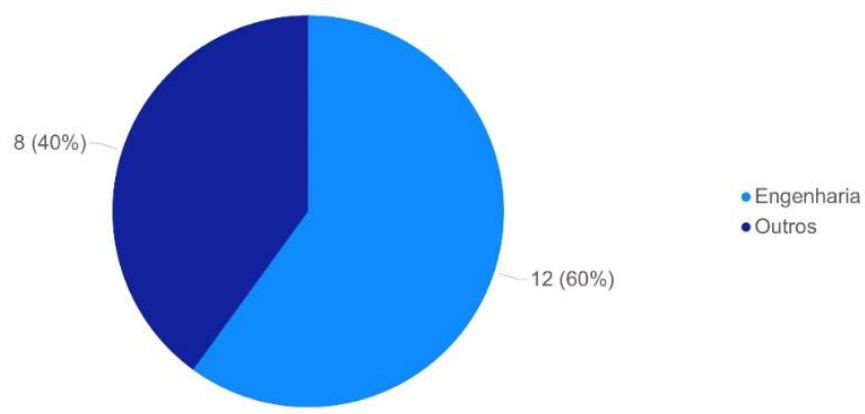

Fonte: Autoral 
Figura 2 - Gráfico ilustrando respostas sobre experiência prévia com o ensino superior.

É seu primeiro curso superior?

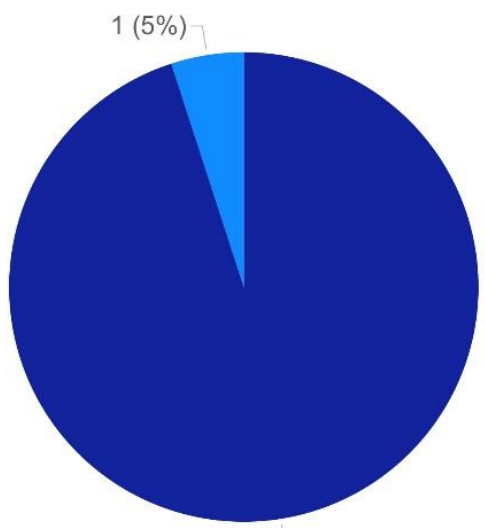

-É meu primeiro curso superio

- Já cursei outro curso mas não me gradue

- Já cursei outro curso e me graduei

Fonte: Autoral

Posteriormente, foram coletados dados sobre o perfil de formação básica dos alunos, objetivando identificar se há alguma correlação entre o número de participantes e a instituição em que cursou o ensino médio. Observou-se, conforme mostrado na Figura 3 , uma maior participação de ex-alunos de escolas públicas, somando $75 \%$ do público total. Desses alunos, apenas um afirmou ter participado de cursos preparatórios para vestibulares.

Além disso, identificou-se maior tendência de interesse no curso por estudantes que ingressaram na Universidade por meio de cotas. Isso está em conformidade com a maior participação de estudantes de escolas públicas, que soma $75 \%$ do público. A Figura 4 , a seguir, evidencia a relação analisada.

Figura 3 - Gráfico ilustrando em qual tipo de escola os participantes se graduaram.

Você se formou no ensino médio em escola pública ou particular?

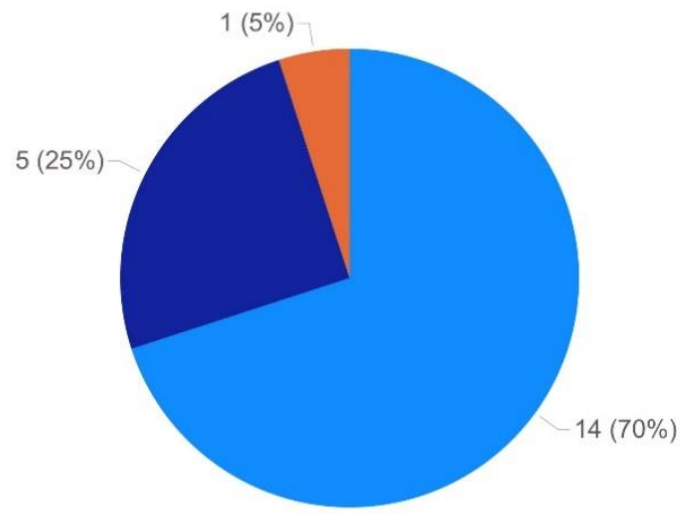

Fonte: Autoral 
Figura 4 - Gráfico ilustrando a modalidade de ingresso na universidade.

Qual foi sua modalidade de ingresso na universidade?

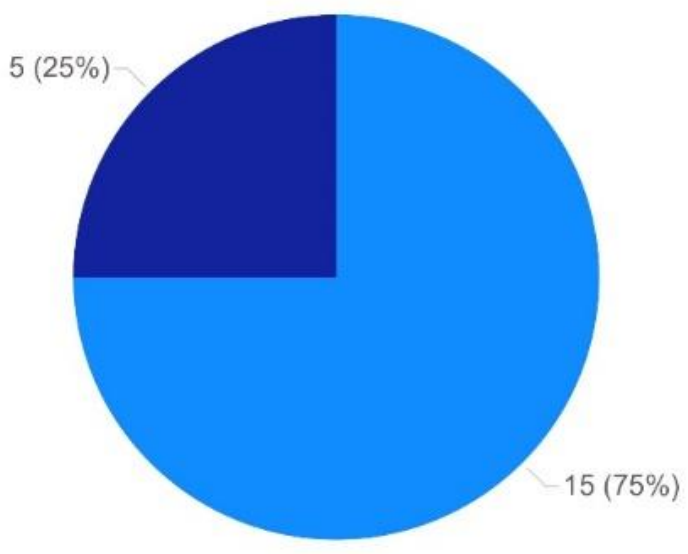

- Cotas sociais e/ou raciais - Ampla Concorrência

Fonte: Autoral

Com a coleta de dados sobre formação básica, perfil demográfico e modalidade de acesso bem definidas, partiu-se para a análise dos dados sobre o desempenho do curso.

\subsection{Impactos e influências do curso nos alunos}

O parâmetro inicial para avaliação da qualidade do curso foi a capacidade de auxílio aos alunos, tanto para as disciplinas atuais prestadas por esses, quanto para a compreensão de tópicos gerais que envolvem as ciências exatas. Para isso, o público pesquisado foi indagado a respeito do desempenho em sua graduação.

Houve unanimidade em afirmar que o curso dispôs melhorias à performance nas disciplinas. No entanto, o público pesquisado dividiu-se quanto ao nível de apoio prestado. Os alunos que afirmaram "muita melhoria" foram levemente superiores aos que afirmaram "pouca melhoria". Esses dados estão dispostos na Figura 5, a seguir.

Figura 5 - Gráfico ilustrando o relato dos alunos com relação à melhora no aprendizado nas disciplinas cursadas após o curso.

O quanto você acha que o curso auxiliou em seu aprendizado nessas disciplinas?

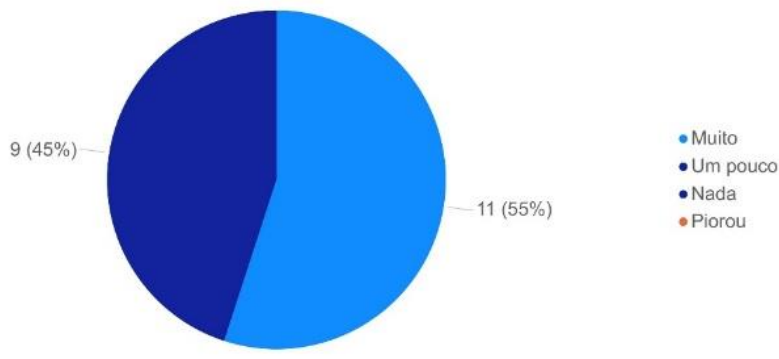

Fonte: Autoral 
Ademais, buscou-se entender sobre como o curso afetou os participantes com relação à temas específicos trabalhados ao longo das aulas. O principal objetivo dessa análise foi diferenciar a compreensão teórica da compreensão prática. A primeira adquirida por assistir passivamente às atividades e, a segunda, por meio da resolução das listas de exercícios disponibilizadas. Esses parâmetros foram usados como base para inferir sobre a forma que os alunos serão capazes de lidar com problemas de natureza matemática no futuro.

Segundo a Figura 6, o grupo novamente dividiu-se com relação à avaliação. A maioria afirma ser capaz de aplicar os conceitos estudados "quase sempre" (50\%) ou "sempre" (15\%), apresentando bons resultados em relação ao conhecimento tanto teórico quanto prático. No entanto, $35 \%$ dos alunos afirmaram "dificuldades ao aplicar", relatando um bom desempenho teórico, mas aquém em relação ao prático. É possível identificar um alto apoio passivo com relação às atividades, porém há necessidade de melhoria quanto à parte ativa do curso.

Figura 6 - Gráfico ilustrando a compreensão que os alunos tiveram dos temas abordados no curso.

\section{Com relação ao conteúdo abordado no curso, assinale qual opção você mais se identifica}

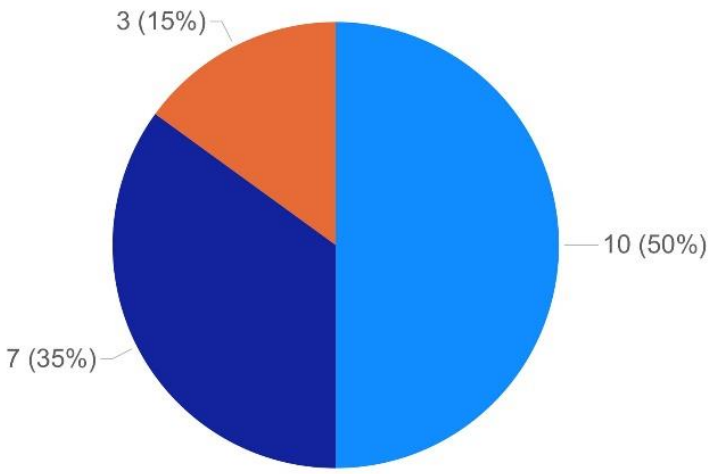

Fonte: Autoral

Em outra frente, buscou-se entender a colaboração do curso de maneira irrestrita à graduação. Dessa maneira, os entrevistados foram questionados quanto à confiança em relação a temas que envolvem ciências exatas.

De forma unanime, houve consenso na melhoria da confiança, sendo $35 \%$ capaz de afirmar uma melhora significativa. No entanto, a grande maioria afirmou um pequeno avanço. Essas porcentagens são esperadas, dado que o curso seria incapaz de cobrir todos os conceitos envolvidos em Matemática, devido à limitação de tempo. Além disso, é de se esperar que o desenvolvimento de confiança com tópicos de ciências exatas não surja imediatamente, mas ao longo de suas experiências estudantis. A Figura 7 apresenta os dados discorridos. 
Figura 7 - Gráfico ilustrando o aumento de confiança em relação à matemática após o curso.

O quanto você classifica que sua confiança com relação à matemática foi afetada pelo curso?

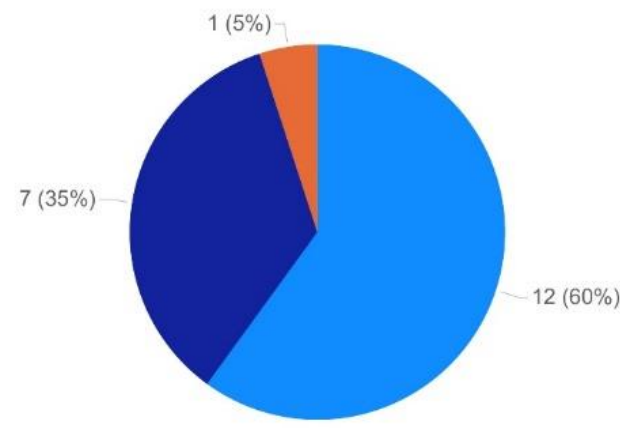

- Melhorou um pouco

- Melhorou significativamente

- Alguma melhora

- Manteve-se igual

- Piorou significativamente

- Piorou um pouco

Fonte: Autoral

Questionou-se, também, sobre o quanto o aluno acreditava que os temas abordados seriam relevantes no âmbito acadêmico e profissional. Essa pergunta visa entender se o aluno está ciente que os tópicos estudados serão úteis futuramente em suas aplicações específicas. A maioria considera os assuntos muito importantes para o desenvolvimento acadêmico e apenas $15 \%$ acreditam ser medianamente importante.

Dado que a maioria dos alunos estavam em períodos iniciais da graduação, verificase certa compreensão por parte desses sobre a relevância dos tópicos. A Figura 8 dispõe 0 analisado.

Figura 8 - Gráfico ilustrando a utilidade do curso para o crescimento acadêmico e profissional.

Você acha que o que Ihe foi ensinado será útil para seu crescimento acadêmico e/ou profissional?

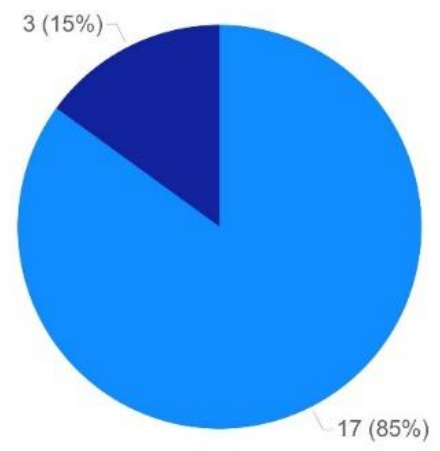

- Muito

- Medianamente

- Nada

-Pouco

Fonte: Autoral 
Analisou-se, também, a qualidade do material didático fornecido, já que esse foi elaborado especificamente para o curso. Uma vez que há necessidade de compreender os temas para avançar academicamente, espera-se que os alunos utilizem o material para consultas futuras. Consoante às expectativas, os entrevistados consideraram o material "muito útil" ou "útil", conforme disposto na Figura 9.

Figura 9 - Gráfico ilustrando o quão útil os alunos consideraram o material fornecido para o curso.

\section{O quão útil você classifica que foi o material fornecido?}

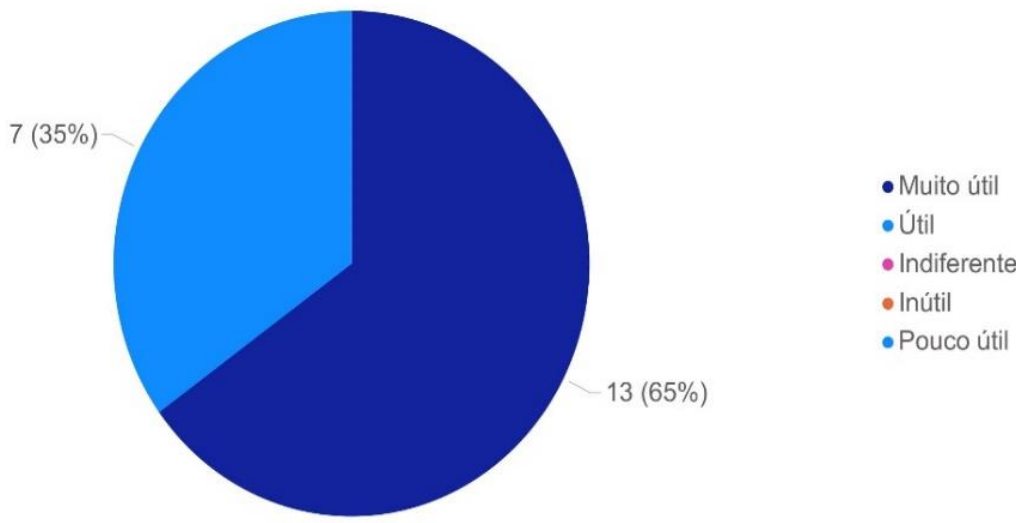

Fonte: Autoral

\subsection{Influências da formação básica no desempenho}

Com a percepção de que a diferença de formação entre os alunos foi um dos principais contrastes em relação ao desempenho nas atividades, decidiu-se abordar este aspecto com maior detalhamento. Primeiramente, a ementa do curso abrangeu 15 diferentes assuntos, os quais foram apresentados aos entrevistados para identificarem quais temas foram estudados ao longo da formação básica.

O estudo prévio dos assuntos é um fator que influencia no domínio do tema, uma vez que pessoas com maior exposição a um determinado assunto, naturalmente, tendem a se desenvolver melhor. Observou-se que os alunos formados em escolas particulares assinalaram cerca de $32 \%$ mais itens do que aqueles oriundos de escolas públicas, em média. Quando comparado com escolas públicas com cursos preparatórios, essa diferença mostrou-se maior, possivelmente devido ao foco objetivo em temas comuns a vestibulares específicos. Os dados são apresentados na Figura 10. 
Figura 10 - Gráfico comparativo sobre a média de conteúdos abordados no ensino médio por tipo de escola

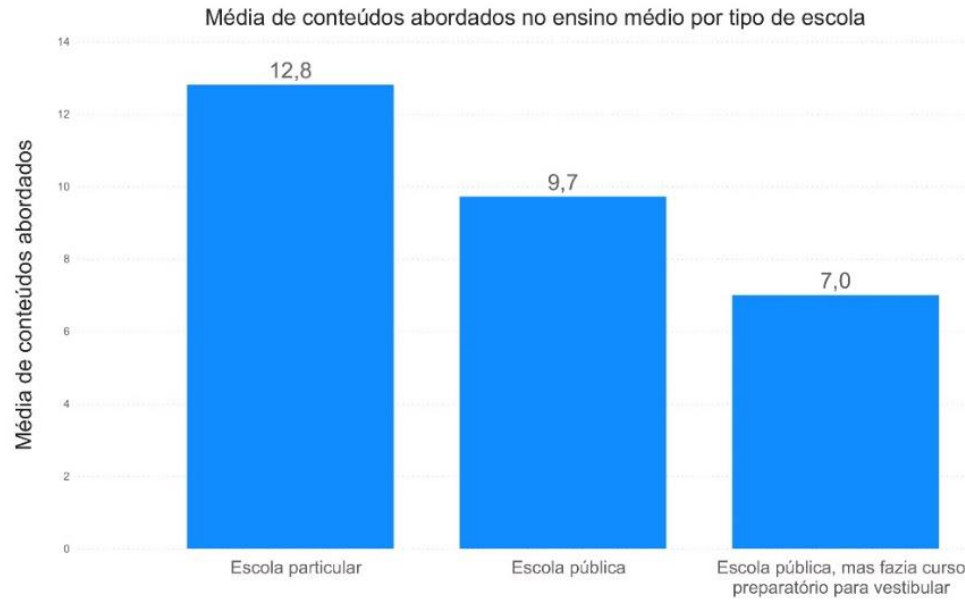

Fonte: Autoral

Também foi observada tendência com relação à confiança promovida pelo curso. A maioria dos alunos de escolas particulares consideraram ter desenvolvido "pouca melhoria" com relação à confiança. Já os estudantes de escolas públicas, tiveram maior porcentagem de "melhora significativa" em relação aos de escolas particulares, mesmo que ainda ficasse aquém dos alunos que registraram alguma melhora, pois houve participantes que relataram indiferença em relação ao curso. A Figura 11 apresenta esses dados.

A comparação entre o comportamento de compreensão e aplicação dos conhecimentos se mostrou distinta entre os diferentes grupos. No grupo de escolas públicas, tem-se presente a maior concentração de pessoas que, apesar de bom domínio passivo, apresenta dificuldade ao aplicar o conhecimento adquirido. Isso pode ser evidenciado na Figura 12.

Figura 11 - Gráfico comparativo entre percepção de melhora na confiança por tipo de escola.

Porcentagem de alunos que notaram melhora na confiança por tipo de escola
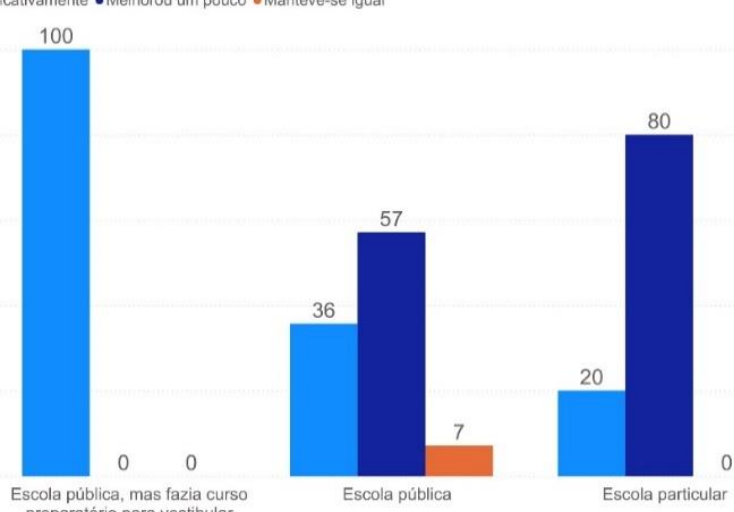

Fonte: Autoral 
Figura 12 - Gráfico comparativo a compreensão dos alunos sobre os temas do curso e suas respectivas formações no ensino básico.

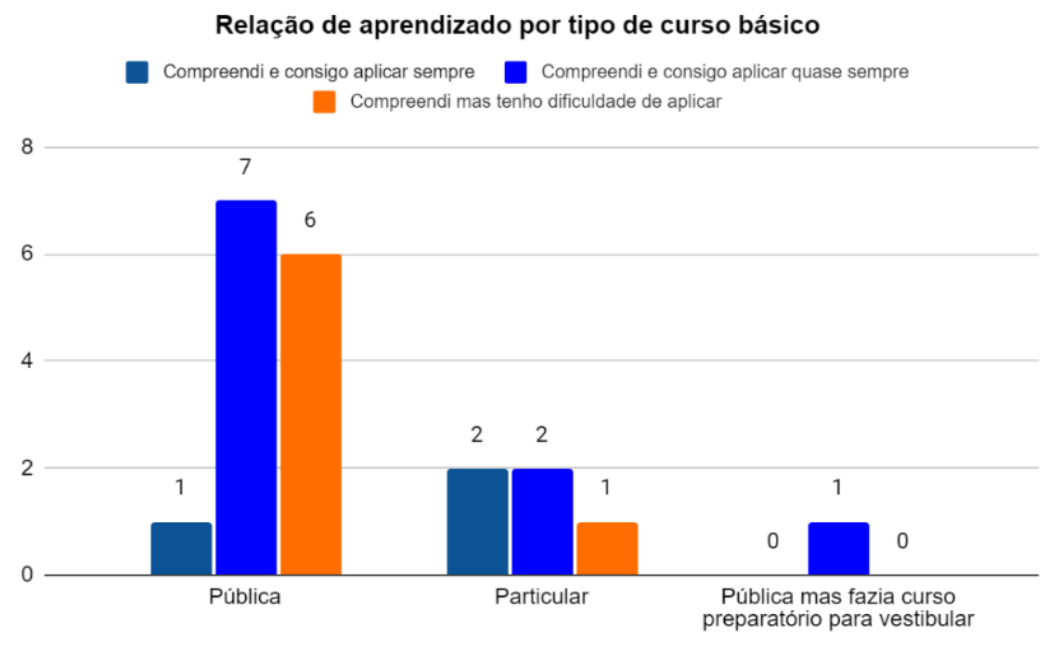

Fonte: Autoral

Por fim, dispôs-se de um gráfico para analisar as categorias de acesso à universidade. Conforme esperado, a maioria dos ingressantes por cotas são estudantes de escolas públicas, conforme explícito na Figura 13.

Figura 13 - Gráfico comparativo entre método de ingresso na universidade por tipo de escola.

Número de alunos de cada modalidade de ingresso na universidade por tipo de escola

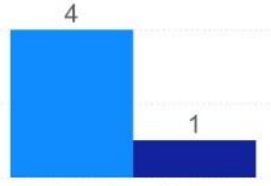

Escola particular

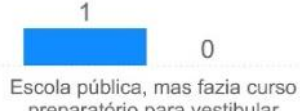
Escola pública, mas fazia curso

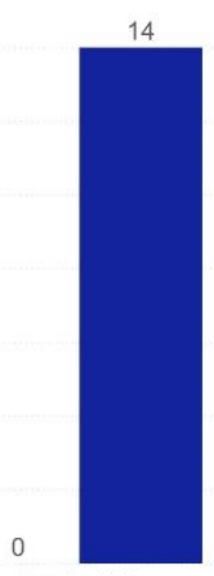

Escola pública

Fonte: Autoral 


\section{CONCLUSÕES}

Os dados coletados demonstraram que o curso de matemática básica promovido pelo grupo PETMEC na Universidade Federal de Uberlândia, de modo geral, impactou positivamente àqueles que participaram. Assim, ao final da atividade, todos os alunos afirmaram ter adquirido maior confiança em relação à matemática. A maioria dos estudantes também afirmou que o curso os auxiliou nas disciplinas básicas de sua graduação e em seu crescimento acadêmico e profissional.

Analisando o perfil dos alunos, observou-se uma diferença entre estudantes formados no ensino público e privado. A participação majoritária de alunos oriundos de escolas públicas parece indicar o maior déficit na educação matemática desse grupo. Tal fator influenciou diretamente nos conhecimentos prévios desses alunos e fez com que eles percebessem uma melhora mais significativa em sua confiança diante dos assuntos apresentados. Por outro lado, após o curso, esses estudantes apresentaram maior dificuldade de aplicar os conceitos apesar da compressão dos tópicos abordados.

\section{Agradecimentos}

Os autores agradecem ao grupo Programa Tutorial e Extensão da Faculdade de Engenharia Mecânica (PETMEC) pelo apoio e realização do curso.

\section{REFERÊNCIAS}

GAMBA, Estêvão. SALDAÑA, Paulo. TAKASHASHI, Fábio. Matemática agrava abismo entre escolas públicas e privadas no Enem. Folha de São Paulo, São Paulo, 9 jul. 2018. Disponível em: <https://www1.folha.uol.com.br/educacao/2018/07/matematica-agravaabismo-entre-escolas-publicas-e-privadas-no-enem.shtml>. Acesso em: 12 abr. 2021.

PAIVA, Manoel Rodrigues. Matemática: Paiva. 2 ed. São Paulo: Moderna, 2010.

PASSO, Fabiana Gomes dos et al. Análise dos Índices de Reprovações nas Disciplinas Cálculo I e Geometria Analítica nos Cursos de Engenharia da Univasf. In: XXXV Congresso Brasileiro de Educação em Engenharia, 2007. Anais. Disponível em: $<$ https://silo.tips/download/analise-dos-indices-de-reprovaoes-nas-disciplinas-calculo-i-egeometria-analitic>. Acesso em: 13 abr. 2021.

Pisa 2018 revela baixo desempenho escolar em Leitura, Matemática e Ciências no Brasil. Portal Mec, Brasília, 03 dez. 2019. Disponível em: <http://portal.mec.gov.br/ultimasnoticias/211-218175739/83191-pisa-2018-revela-baixo-desempenho-escolar-em-leituramatematica-e-ciencias-no-brasil>. Acesso em: 11 abril. 2021.

REZENDE, W. M. O Ensino de Cálculo: Dificuldades de Natureza Epistemológica. 2003. Tese (Doutorado) - Faculdade de Educação -USP, São Paulo, 2003a. Disponível em: <http://flacso.org.br/files/2017/08/WANDERLEY_REZENDE.pdf>. Acesso em: 13 abr. 2021.

Só $44 \%$ dos alunos de engenharia da última década terminaram o curso. G1, São Paulo, 27 jul. 2013. Disponível em: <http://g1.globo.com/educacao/noticia/2013/07/so-44-dosalunos-de-engenharia-da-ultima-decada-terminaram-o-curso.html>. Acesso em: 12 abr. 2021. 
Abstract: This article aims to evaluate the impacts of applying a basic mathematics course on the performance of students in the disciplines of exact sciences, mainly for engineering courses. We studied characteristics that would be relevant in the performance of students, such as the type of basic training, whether there was support for pre-university entrance courses, their performance both in the course itself, and in the disciplines to which they are enrolled. The data presented were arranged in order to identify the main obstacles to a good development in matters associated with mathematics. The results showed a discrepancy between students from public and private schools. Even so, most students reported some improvement with respect to mathematics and confidence in the discipline.

Keywords: Basic mathematics course, Influence on learning, Performance of students in exact sciences. 